\title{
Magnetic and ground penetrating radar for the research of Medieval buried structures in Marche Region
}

\author{
M. Bavusi ${ }^{1}$, A. Loperte $^{1}$, V. Lapenna ${ }^{1}$, U. Moscatelli ${ }^{2}$, and S. Minguzzi ${ }^{3}$ \\ ${ }^{1}$ Consiglio Nazionale delle Ricerche, Istituto di Metodologie per l'Analisi Ambientale (IMAA), C. da S. Loja, Tito \\ Scalo (PZ), Italy \\ ${ }^{2}$ Dipartimento di Beni Culturali, Università di Macerata, Fermo, Italy \\ ${ }^{3}$ Dipartimento di Storia e Tutela dei Beni Culturali, Udine, Italy
}

Received: 15 January 2010 - Revised: 29 January 2010 - Accepted: 2 February 2010 - Published: 29 April 2010

\begin{abstract}
A magnetic and Ground Penetrating Radar joint survey was carried out in the framework of the R.I.M.E.M. project that has the aim of supporting the archaeological prospections and drive the selection of the excavation areas related to the Late Roman Period and Early Middle Ages in the Central and Southern Italy. In particular, this papers deals with the magnetic surveys acquired near "Madonna della Valle" and GPR and magnetic joint surveys carried out in "Monastero"site. Most of magnetic maps carried out in "Madonna della Valle" site shown the absence of structured magnetic anomalies, despite of the presence of archaeological signs. Several hypothesis were given to explain this evidence.

Joint interpretation performed in "Monastero" site shown more intense magnetic anomalies related with shallower reflections due to probably to buried pipes. Other reflections are related with magnetic anomalies compatible with archaeological targets, but some significant reflections do not correspond to any magnetic anomaly, indicating magnetic method could be "blind" respect the archaeological target.

New field surveys including the electrical resistivity tomography could be carried out in order to overcome these acquisition and interpretation difficulties.
\end{abstract}

\section{Introduction}

This work was carried out in the framework of the R.I.M.E.M. project (Research on Medieval settlements in the inland of the Marche Region, Italy) leaded by the Universities of Macerata and Udine; the project aims to producing a significant contribution for the comprehension of the

Correspondence to: M. Bavusi

bavusi@imaa.cnr.it settlement process in the Central and Southern Italy during the Late Roman Period and Early Middle Ages (Gnesi et al., 2007).

In this framework a geophysical survey was planned in order to support the archaeological prospections and drive the selection of the excavation areas. Magnetic and Ground Penetrating Radar (GPR) surveys were carried out in the area included amongst the municipal districts of Caldarola, Cessapalombo and San Ginesio, sited in the area closed to Macerata city, between the valleys of Chienti and Fiastra rivers.

In particular, this work describes the geophysical surveys acquired near "Madonna della Valle" and "Monastero" (Fig. $1 \mathrm{~A}$ and B).

In "Madonna della Valle" site, an extensive gradiometric survey were carried out, by using the vapour caesium magnetometer Geometrics G-858 in gradiometric configuration.

In the "Monastero" site a detailed gradiometric mapping was supported by a GPR 3-D survey thanks to the GSSI SIR System with a central frequency antenna of $400 \mathrm{MHz}$ mounted on survey cart with survey wheel odometer.

Magnetic method is now a standard tool in the archaeological prospecting due to its advantages in terms of nondestructivity, quickness and capability of mapping wide areas in quite a short lapse of time (Bavusi et al., 2008). Moreover the method is able to provide information that can be well related with remote sensing data (Gallo et al., 2008).

Due to its non invasivity and low time-consuming, GPR method is well appreciated in the archaeological community (Basile et al., 2000). The integrations of several geophysical methods are usual (Sambuelli et al., 1999; De Domenico et al., 200; Chianese et al., 2004) particularly when a simple comparison in cross section along the same profiles can be performed. Moreover, GPR is suitable to obtain several 3-D representations (Nuzzo et al., 2002).

Published by Copernicus Publications on behalf of the European Geosciences Union. 


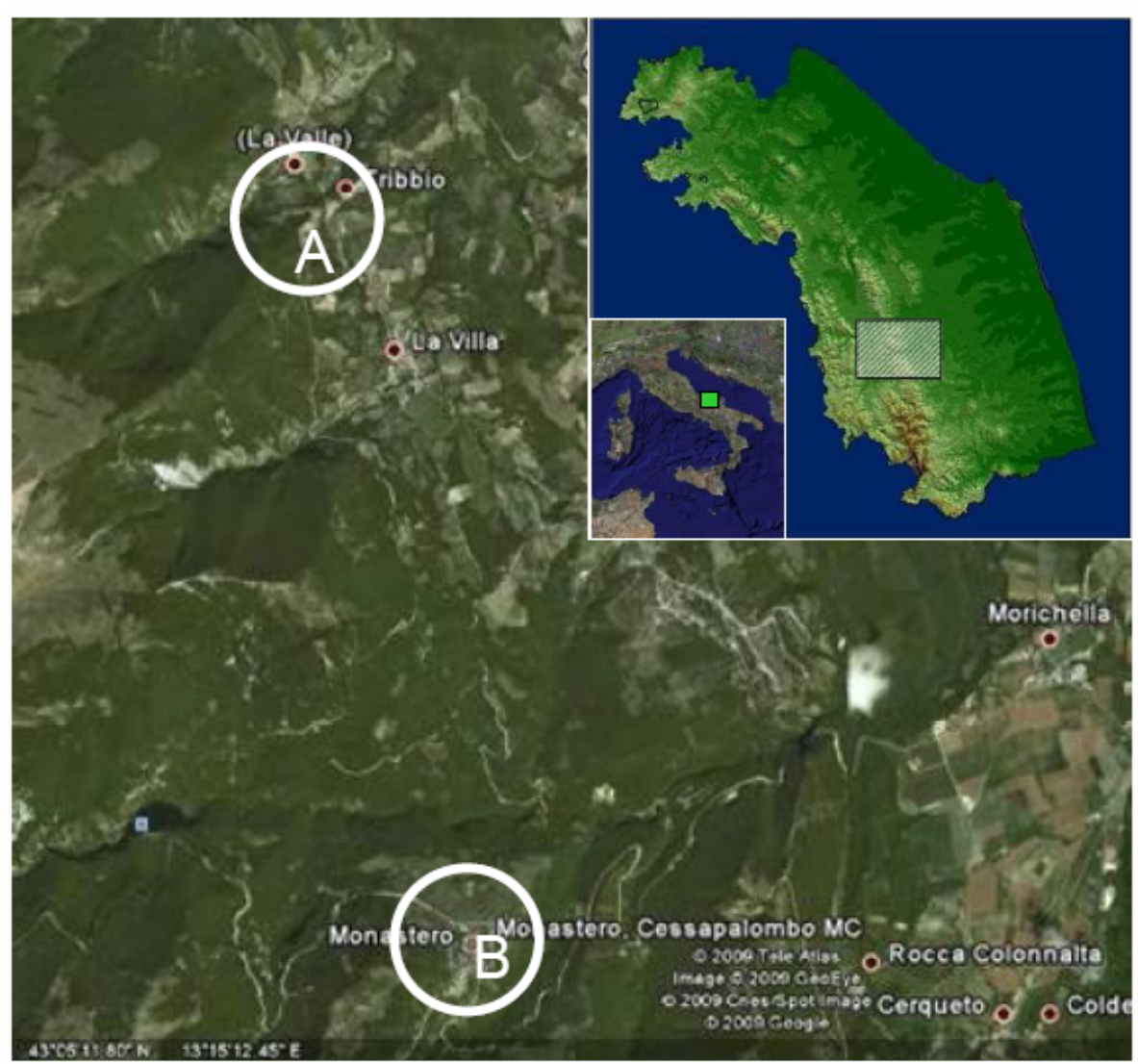

Fig. 1. Location of surveyed archaeological sites.
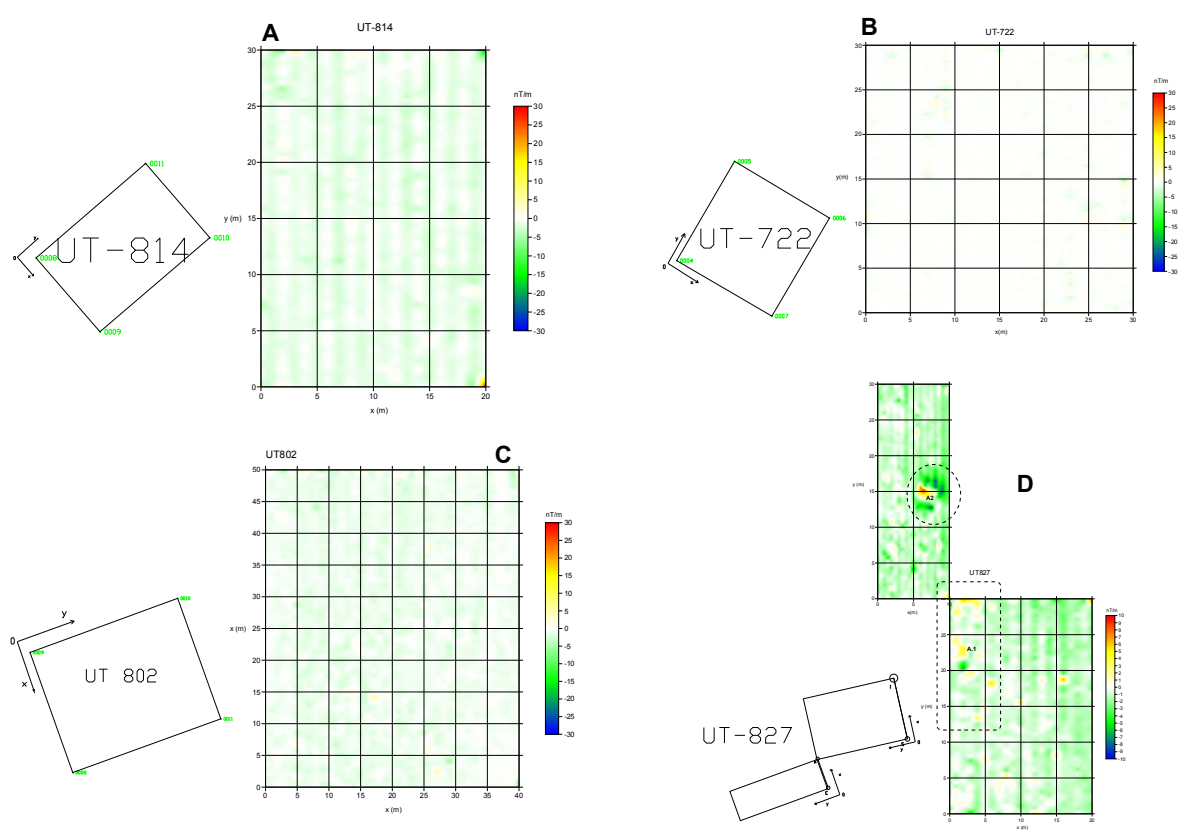

Fig. 2. Magnetic maps and simplified acquisition schemes carried out in the "Madonna della Valle" site. 

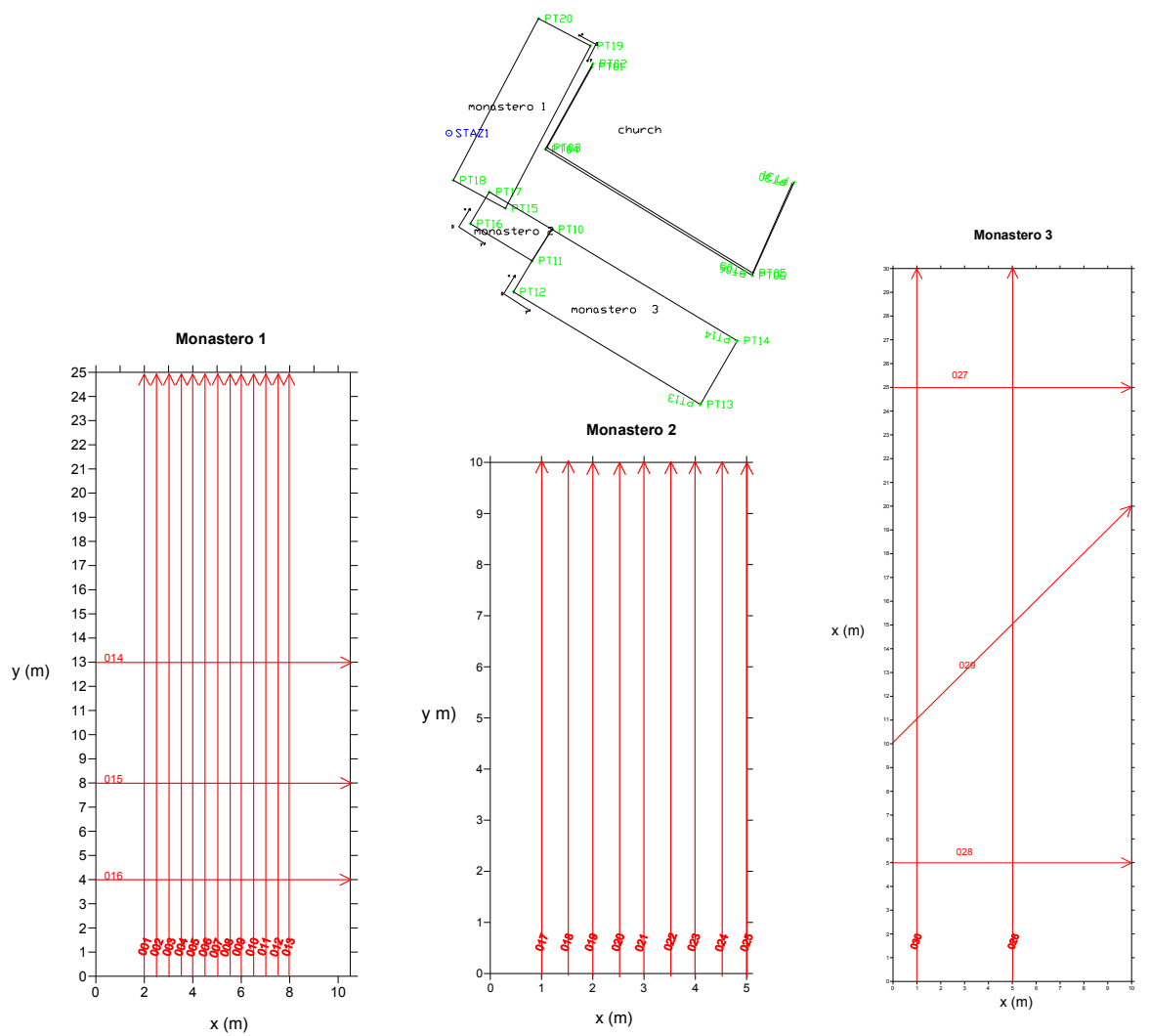

Fig. 3. Magnetic and GPR survey design used in "Monastero" site.

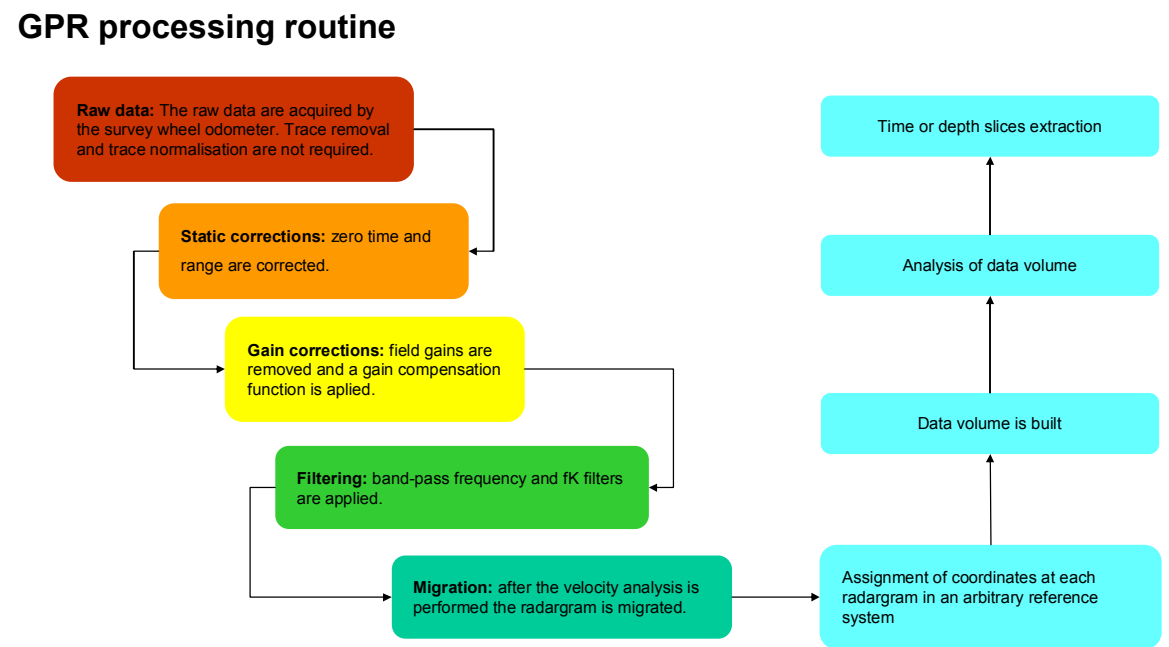

Fig. 4. Example of GPR data processing needed to obtain time or depth slices.

In the case at hand, the acquisition stage consists of several parallel profiles (radargram) closed spaced $(0.5-1.0 \mathrm{~m})$. Further processing stage can be very complex but it is fundamental to obtain easily interpretable 2-D images and 3-D reconstructions. The result of a 3-D GPR acquisition/processing can be given in terms of "time-slices" or "depth-slices", i.e. slices from different times/depths. A time-slice is easily comparable with a magnetic map. 

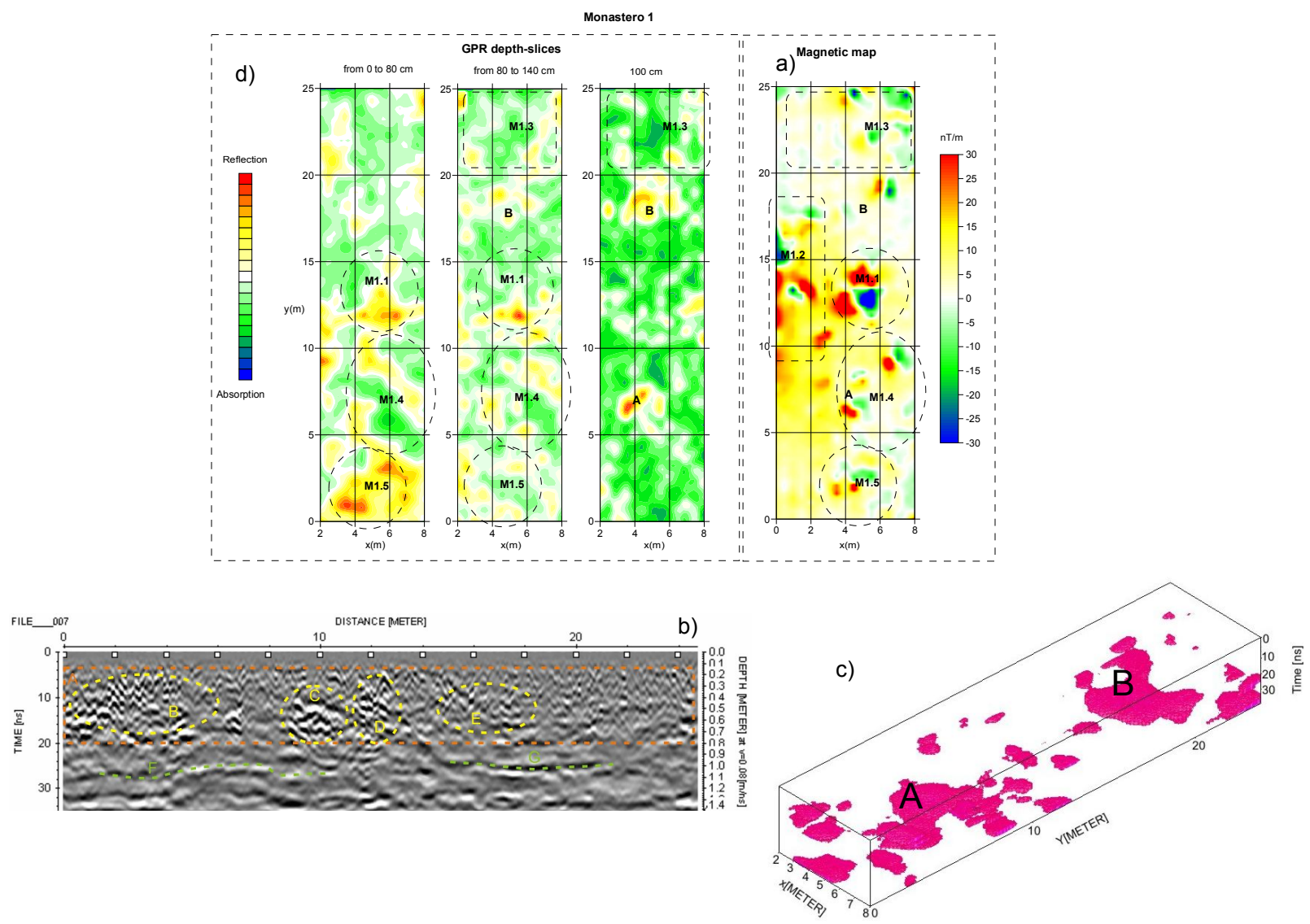

Fig. 5. Geophysical data acquired in "Monastero1" site. (a) magnetic map; (b) radargram; (c) GPR data volume; (d) depth-slices built from 0 to $80 \mathrm{~cm}$ of depth, from $80 \mathrm{~cm}$ to $140 \mathrm{~cm}$ of depth and at $100 \mathrm{~cm}$ of depth. Labels explanation in the text.

\section{Extensive gradiometric survey at Madonna della Valle}

The extensive gradiometric survey planned in "Madonna della Valle" included the maps listed in Table 1.

All maps were acquired along a regular mesh constituted by parallel survey lines distant $1 \mathrm{~m}$ by using the caesium vapour Magnetometer Geometrics G858 in gradiometric configuration that provides a sensitivity of $0.1 \mathrm{nT} / \mathrm{M}$. Sampling interval was of $0.25-0.3 \mathrm{~m}$ about as consequence of the sampling rate of $5 \mathrm{~Hz}$ combined with the velocity of the operator.

Magnetic data processing included despike, filtering and destripe. Finally the data were interpolated by using Kriging algorithm. Figure 2 shows the results. Low gradiometric intensities are showed in the most part of the surveyed areas. Only the UT-827 area shown a significant anomaly, but the intensities are very low $(+/-10 \mathrm{nT} / \mathrm{m})$. Geophysical evidences are in disagreement with the archaeological ones showing a great amount of pottery fragments as in the site UT-802 where no magnetic anomalies are detected. Unfortunately, the presence of ploughing in all investigated sites made it not possible further GPR surveys.
Table 1. Magnetic maps carried out in "Madonna della Valle" site.

\begin{tabular}{lccc}
\hline Map & Location & Line spacing & $\begin{array}{c}\text { Dimensions } \\
\mathrm{b} \cdot \mathrm{h}(\mathrm{m})\end{array}$ \\
\hline UT814 & A & $1 \mathrm{~m}$ & $20 \cdot 30$ \\
UT722 & A & $1 \mathrm{~m}$ & $30 \cdot 30$ \\
UT802 & A & $1 \mathrm{~m}$ & $40 \cdot 50$ \\
UT 827 & A & $0.5 \mathrm{~m}$ & $20 \cdot 30+10 \cdot 30$ \\
\hline
\end{tabular}

\section{Detailed gradiometric and ground penetrating radar survey at Monastero}

In "Monastero" site three detailed magnetic maps, named "Monastero 1", "Monastero 2" and "Monastero 3" were carried out with the same setting adopted for "Madonna della Valle" site, but the line spacing was of $0.5 \mathrm{~m}$ (Table 2).

Also, a 3-D GPR survey was carried out in correspondence of the maps "Monastero 1" and "Monastero 2" by using a GSSI SIR 3000 unit equipped with a $400 \mathrm{MHz}$ 


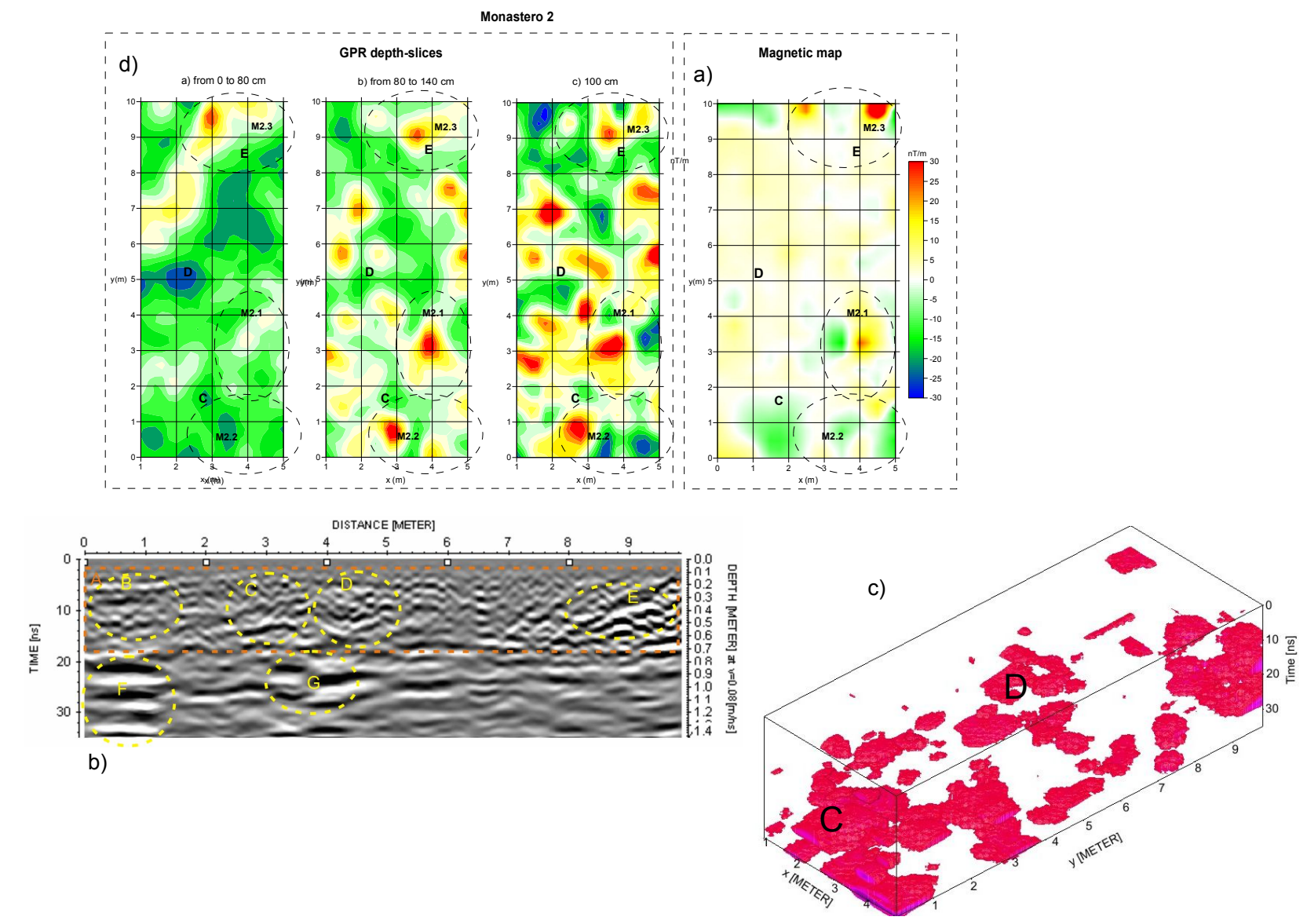

Fig. 6. Geophysical data acquired in "Monastero 2" site. (a) magnetic map; (b) radargram; (c) GPR data volume; (d) depth-slices built from 0 to $80 \mathrm{~cm}$ of depth, from $80 \mathrm{~cm}$ to $140 \mathrm{~cm}$ of depth and at $100 \mathrm{~cm}$ of depth. Labels explanation in the text.

central frequency antenna mounted on cart with survey wheel odometer. In addition, a 2-D GPR survey was carried out in correspondence of "Monastero 3" (Fig. 3).

The GPR system has been set with $32 \mathrm{scan} / \mathrm{m}, 512 \mathrm{sam}$ ples/scan and $16 \mathrm{bit} / \mathrm{sample}$; field gains, $50 \mathrm{~ns}$ of range and an automatic zero positioning have been applied. The detailed GPR survey was needed to improve the interpretability of the magnetic data. In fact, a complex processing routine was carried out in order to get both data volumes and time slices, more easily comparable with magnetic maps (Fig. 4).

\subsection{Monastero 1 site}

Figure 5a shows the magnetic map of "Monastero 1" site. More anomalies (M1.1, M1.4, M1.5) are associable with modern pipelines. On the contrary, M1.3 is compatible in terms of gradiometric intensities with an archaeological target. In Fig. 5b is depicted a radargram of "Monastero 1 " site where it is possible to observe a zone (A) placed between 10 and $80 \mathrm{~cm}$ riche en hyperbolic reflections (B, C, D, E). A deeper zone shows more attenuated sub horizontal reflectors (f, g). The interface at $80 \mathrm{~cm}$ could be re- lated to the water-table. In order to speed the interpretation of GPR data and its correlation with the magnetic one, volumes of data was built by interpolating all radargrams of Monastero" where two main reflections are visible (Fig. 5c). Then, from the data volume three dept-slices were extracted, respectively in the intervals $10-80 \mathrm{~cm}, 80-140 \mathrm{~cm}$ and at $100 \mathrm{~cm}$. Figure $5 \mathrm{~d}$ shows the three depth-slices of "Monastero 1 site": the reflections a and b of Fig. $5 \mathrm{c}$ were recognized at $100 \mathrm{~cm}$ of depth where the intense magnetic anomalies can be referred to metallic objects. Moreover, more intense anomalies (M1.1, M1.4, M1.5) are associable with shallower reflections. M1 could be associated to a buried pipe. M1.3 is compatible in terms of gradiometric intensities with an archaeological target.

\subsection{Monastero 2 site}

Figure 6 shows a similar dataset for "Monastero 2" site: magnetic map shows three noticeable anomalies (denoted by M2.1, M2.2 and M2.3), but their shape and intensity does not allows a precise interpretation (Fig. 6a). 
a)

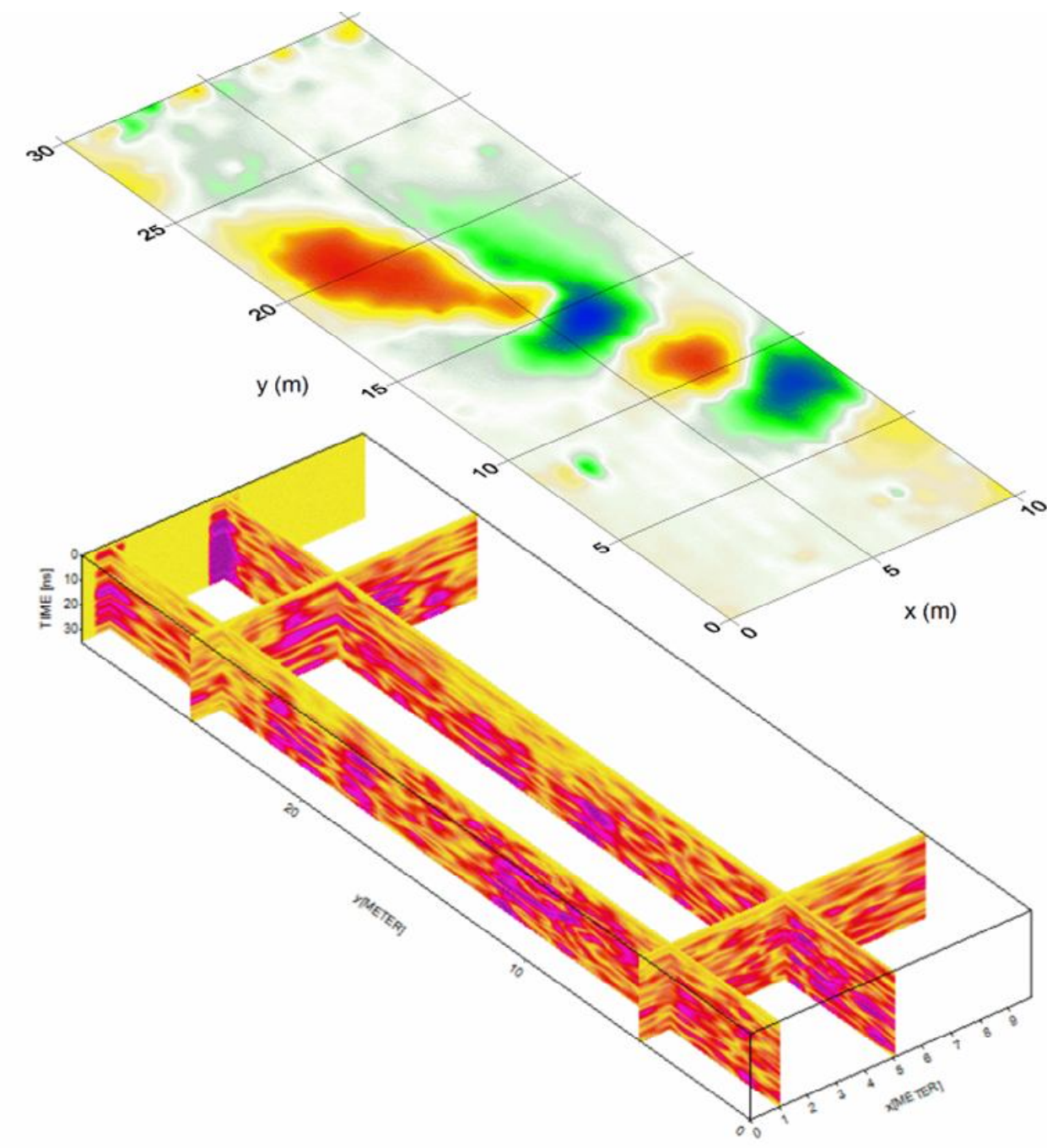

c)

b)

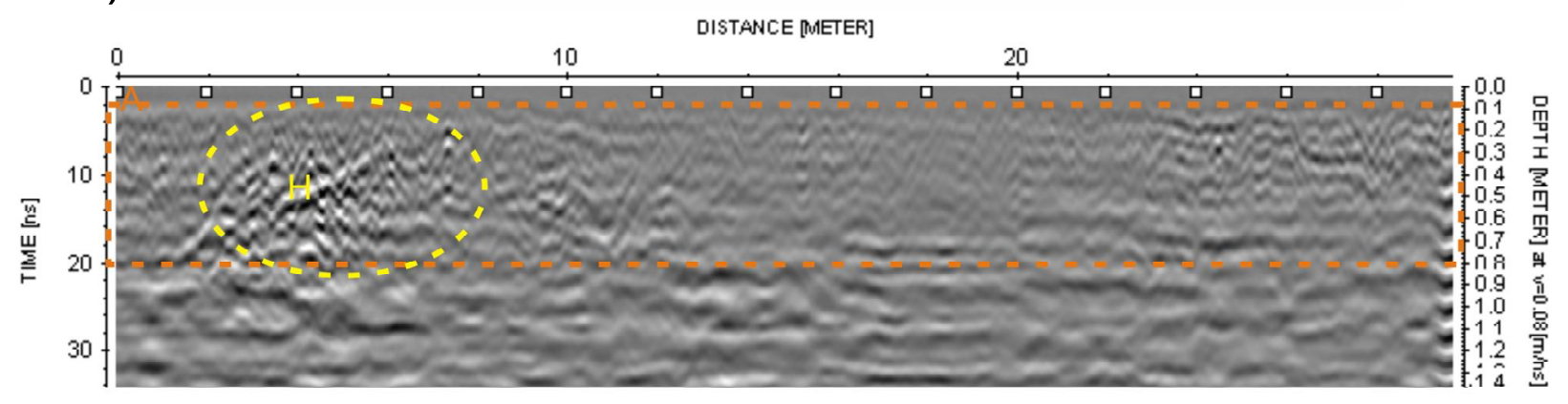

Fig. 7. Geophysical data acquired in "Monastero2" site. (a) magnetic map; (b) radargram; (c) pseudo-3-D GPR reconstruction.

Figure 6b shows a radargram of the "Monastero 2" dataset showing a shallower zone (denoted by a) up to $80 \mathrm{~cm}$ of depth with many sub-horizontal reflections interacting with several diffractions due to probably to the small size $(20-30 \mathrm{~cm})$ of the targets (denoted by b, c, d, e). At a depth larger than $80 \mathrm{~cm}$, where the water table is probably intercepted, a low frequency component prevails and sub-horizontal reflectors locally assuming more intense amplitudes (denoted by F, G) are associable to buried objects. In Fig. 6c a data volume build up of GPR datasets shows three main zones of reflections.

Figure $6 \mathrm{~d}$ depicts the three depth slices of extracted from the data volume of "Monastero 2" site: reflections C and E of Fig. 6c can be related with strong magnetic anomalies (M2.2, 
Table 2. Magnetic maps and GPR datasets carried out in "Monastero" site.

\begin{tabular}{lccc}
\hline Map & Location & $\begin{array}{c}\text { Line } \\
\text { spacing }\end{array}$ & $\begin{array}{c}\text { Dimensions } \\
\mathrm{b} \cdot \mathrm{h}(\mathrm{m})\end{array}$ \\
\hline Monastero 1 & $\mathrm{B}$ & $0.5 \mathrm{~m}$ & $8 \cdot 25$ \\
Monastero 2 & $\mathrm{B}$ & $0.5 \mathrm{~m}$ & $5 \cdot 10$ \\
Monastero 3 & $\mathrm{B}$ & $0.5 \mathrm{~m}$ & $10 \cdot 30$ \\
\hline
\end{tabular}

M2.3) related to metallic objects. The reflections indicated with D corresponds to gradiometric intensities compatible with an archaeological target.

\subsection{Monastero 3 site}

Finally, in Fig. 7a, magnetic map of "Monastero 3" site shows an alignment of intense dipoles due to a modern pipeline. GPR data were firstly interpreted in section view where a shallow zone (A) up to $80 \mathrm{~cm}$ of depth containing localized reflections $(\mathrm{H})$ and a deeper zone showing a more pronounced attenuation due to probably to the water-table (Fig. 7b). Performed survey design does not allow to build a true 3-D representation in "Monastero 3" site. However A pseudo-3D representation is possible to compare magnetic and GPR data (Fig. 7c). The radargram oblique (n. 29) doesn't shown for clarity. Several intense reflections appear in the radargrams but magnetic data is compromised by the intense pipe anomaly.

\section{Conclusions}

Several magnetic maps were carried out in the framework of the R.I.M.E.M. project supported, where local conditions were favourable, by a GPR survey in the Marche Region (Italy).

All magnetic maps carried out in "Madonna della Valle" site, with the exception of the UT- 827 area, showed the absence of structured magnetic anomalies. Nevertheless, archaeological evidences such as a great amount of pottery, suggest the presence of ancient settlements.

Several hypotheses were formulated to give explanation of this evidence:

1. archaeological sterility of the surveyed sites;

2. high thickness of colluvium;

3. low magnetic permittivity contrast between buried target and host medium;

4. destruction of archaeological remains operated by the ploughing;

5. large use of wood in the buildings of the past;
6. combination of the previous hypotheses.

Magnetic maps carried out in "Monastero" site were supported by a 3-D GPR survey. Joint interpretation showed that more intense magnetic anomalies are related with shallower reflections. For this reason they have been correlated to buried pipes. Other reflections are related with magnetic anomalies compatible with archaeological targets, but some significant reflections are not representative of magnetic anomaly, indicating that magnetic method could be "blind" with respect to these archaeological targets.

In the light of these difficulties, further geophysical surveys such as Electrical Resistivity Tomography, Earth Resistance surveys, Magnetic Susceptivity survey and tests excavations are needed starting from more significant sites such as UT-827 and "Monastero".

Acknowledgements. This work was financed by the University of Macerata in the framework of RIMEM project (Research on Medieval settlements in the inland of the Marche Region, Italy) carried out by the University of Macerata and University of Udine.

Edited by: L. Eppelbaum, N. Masini, and F. Soldovieri

Reviewed by: two anonymous referees

\section{References}

Bavusi, M., Giocoli, A., Rizzo, E., and Lapenna, V.: Geophysical characterisation of Carlo' s V Castle (Crotone, Italy), J. Appl. Geophys., 67, 386-401, 2009.

Carrozzo, M. T., Negri, S., Nuzzo, L., Quarta, T., and Villani, A. $\mathrm{V}$ : A ground-penetrating radar survey for archaeological investigations in an urban area - Lecce, Italy, J. Appl. Geophys., 44, 15-32, 2000.

Chianese D., D'Emilio, M., Di Salvia, S., Lapenna, V., Ragosta, M., and Rizzo, E.: Magnetic Mapping, Ground Penetrating Radar Surveys and Magnetic Susceptibility Measurements for the Study of the Archaeological Site of Serra di Vaglio (Southern Italy), J. Archaeol. Sci., 31, 633-643, 2004.

De Domenico, D., Giannino, F., Marino, A., Nuzzo, L., and Rizzo, E.: Indagini elettriche e radar: integrazione dei metodi nello studio dei resti sepolti del monastero normanno in s. Marco D'Alunzio (Messina), Atti del $21^{\circ}$ Convegno Nazionale del GNGTS, 351-353, 2001.

Gallo, D., Ciminale, M., Beckerb, H., and Masini, N. : Remote sensing techniques for reconstructing a vast Neolithic settlement in Southern Italy, J. Arhceol. Sci., 46(1), 43-50,2008.

Gnesi, D., Minguzzi, S., Moscatelli, U. and Virgili, S.: Ricerche sugli insediamenti medievali nell'entroterra marchigiano, Archeologia Medievale, 34, 113-140, 2007.

Nuzzo, L., Leucci, G . Negri, S., Carrozzo, M. T., and Quarta, T.: Application of 3D visualization techniques in the analysis of GPR data for archaeology, Ann. Geophys.-Italy, 45(2), 321-337, 2002.

Sambuelli, L., Socco, L. V., and Brecciaroli, L.: Acquisition and processing of electric, magnetic and GPR data on a Roman site (Victimulae, Salussola, Biella), J. Appl. Geophys., 41, 189-204, 1999. 